\title{
Multiple painless masses
}

\section{Munish Chitkara • Paula J. Rackoff • Luis S. Beltran}

Published online: 7 December 2013

(C) ISS 2013

\section{Part I - Question}

Multiple painless masses

A 67 year old male presented to his primary care physician complaining of several non-painful subcutaneous firm masses on his forearms and legs, some of which he felt were increasing in size over the past few years (Figs. 1, 2, 3, and 4).

The diagnosis can be found at doi: 10.1007/s00256-013-1788-z

M. Chitkara $(\varangle) \cdot$ L. S. Beltran

Department of Radiology, NYU Langone Medical Center

and Hospital for Joint Diseases, 301 East 17th Street,

New York, NY 10003, USA

e-mail: munish.chitkara@nyumc.org

\section{P. J. Rackoff}

Department of Medicine-Rheumatology Division,

NYU Langone Medical Center and Center for Musculoskeletal Care, New York, NY, USA

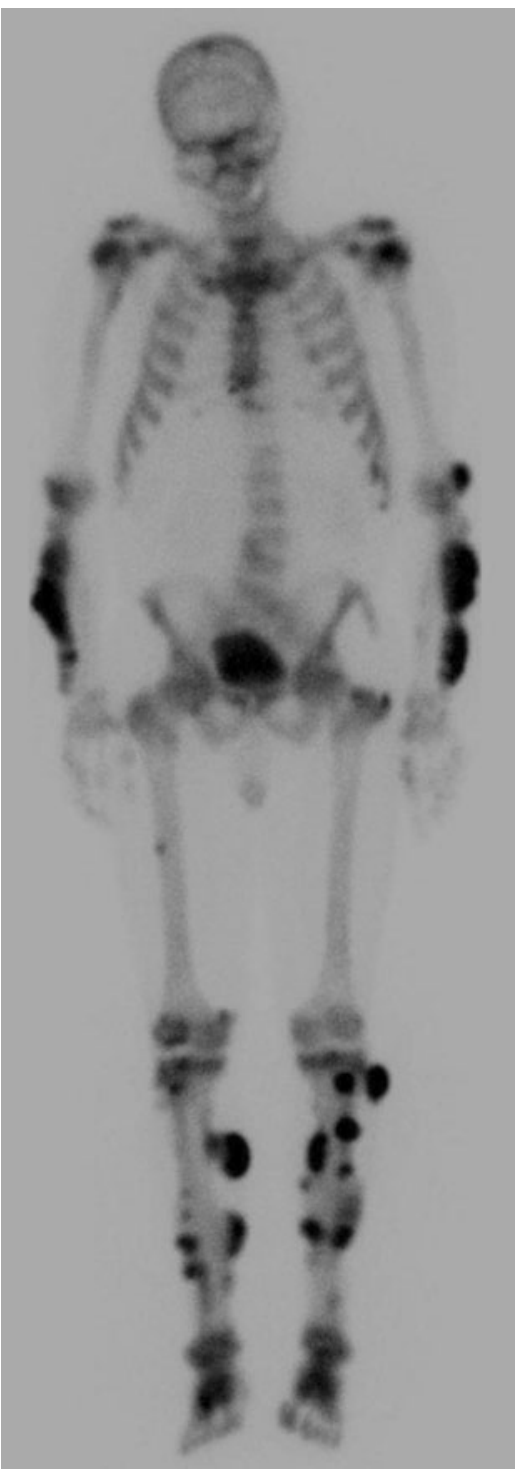

Fig. 1 Anterior view from a whole body 99mTc-methylene diphosphonate bone scan 


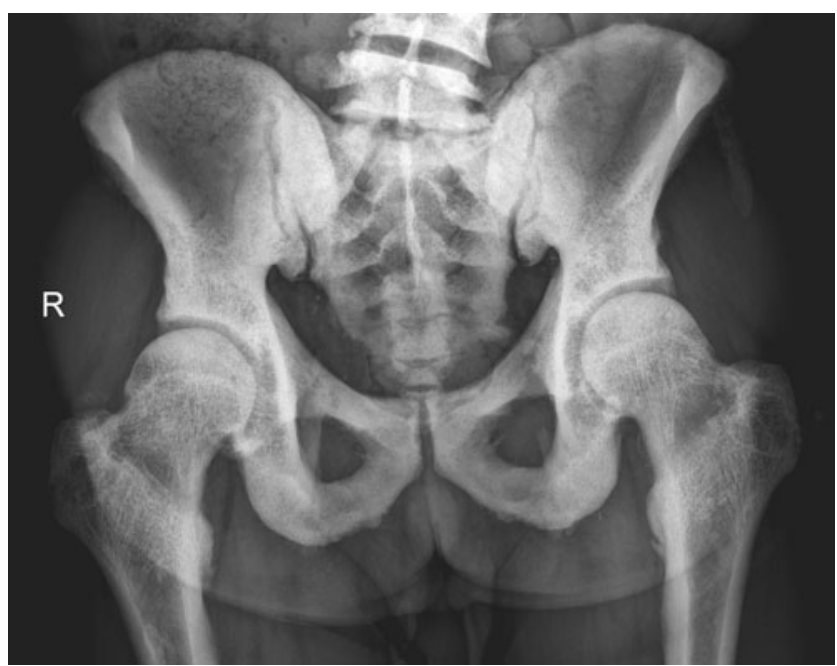

Fig. 2 AP radiograph of the pelvis
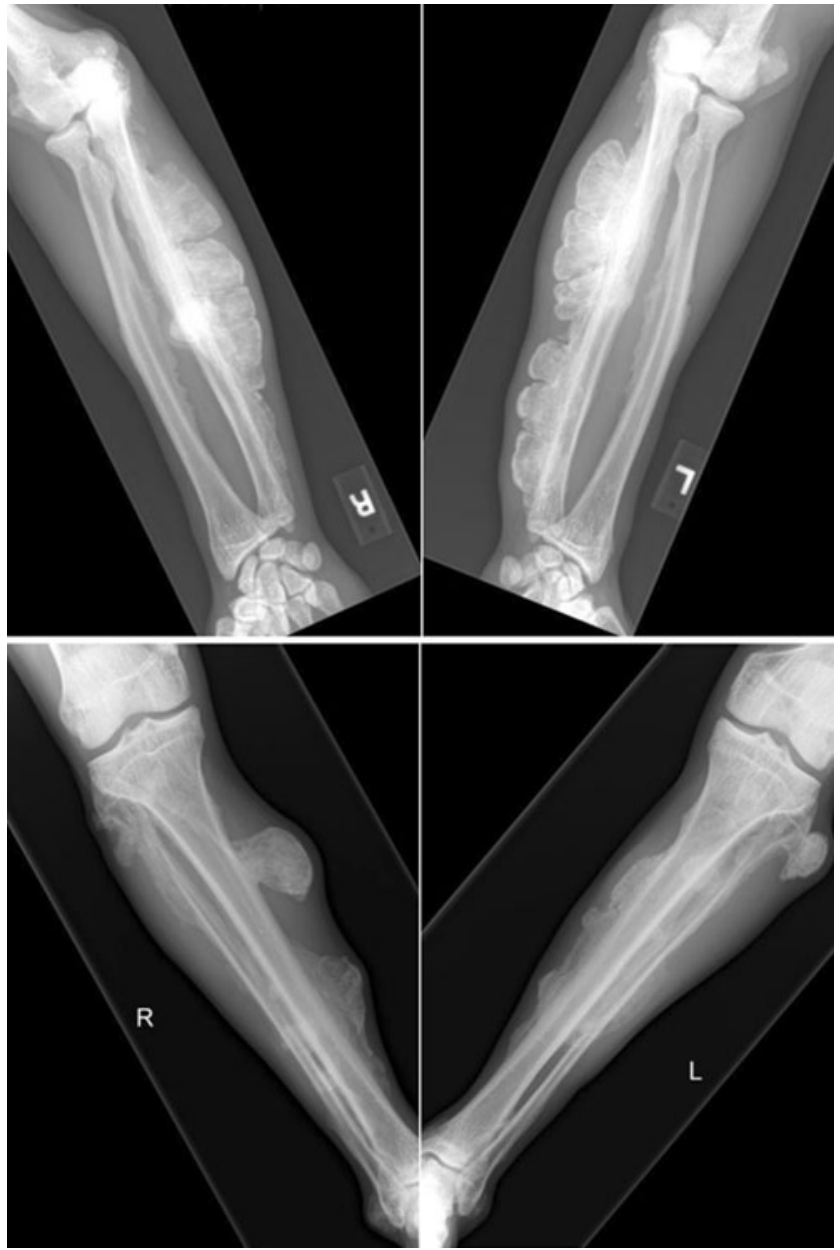

Fig. 3 AP radiographs of the bilateral forearms and lower legs

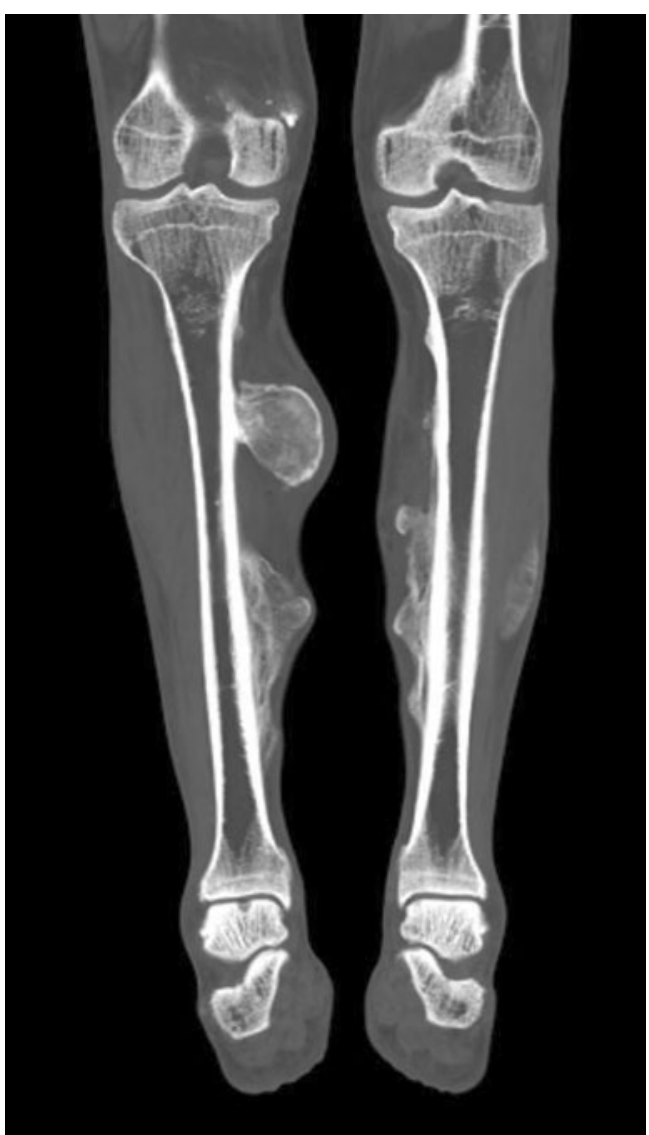

Fig. 4 Coronal CT image of the bilateral lower legs on a bone window

Disclosure The authors declare that they have no conflict of interest. 